Trivent Publishing

(C) The Authors, 2016

Available online at http://trivent-publishing.eu/

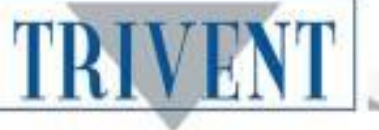

Series: Philosophy, Communication, Media Sciences

Volume: Communication Today: An Overview from Online Journalism to Applied Philosophy

\title{
Disciplinarian Thinking, Inter-Disciplinarity and Multi-Disciplinarity Revisited, with Complexity in Mind
}

\author{
Michael Finkenthal \\ Johns Hopkins University, Baltimore, USA
}

\begin{abstract}
This paper discusses the concept of disciplinarian thinking (DT) in the context of inter and multidisciplinarian (IDT and MDT) endeavors in Humanities and Social, Cultural and Political complex systems. It is shown that IDT and MDT cannot solve, as long as they are based on DT the problems posed by complexity. While moving from one discipline to another, whether we change or not the meaning of the concepts used, we conserve their single-valued character. Multi-disciplinarity, in the way defined here, turns out to be indeed a necessary tool for approaching complexity but it is by no means sufficient.
\end{abstract}

\section{Keywords:}

Complexity; disciplinarian thinking; inter and multi-disciplinarity.

This is an Open Access article distributed in accordance with the Creative Commons Attribution Non Commercial (CC-BY-NCND 4.0) license, which permits others to copy or share the article, provided original work is properly cited and that this is not done for commercial purposes. Users may not remix, transform, or build upon the material and may not distribute the modified material (http://creativecommons.org/licenses/by-nc/4.0/)

DOI: 10.22618/TP.PCMS.20164.349024 
In a book dedicated to interdisciplinarity I tried to arrive to a definition of this concept based on disciplinarian thinking (DT in the following). Briefly, DT is a way of thinking originating in pre-modern times which became dominant after the Newtonian- Galilean (NG) revolution, at the end of the Renaissance. DT is characterized by the fact that its operational concepts are flexible, adaptable (I used at times the term 'phantasmic' concepts) to methodologies specific to given domains of inquiry. In the case of natural ('hard') sciences, the methodology is chosen in a way that makes it easily adjustable to mathematical language. Finally, DT is driven by a purpose oriented built-in structure; therefore it has a teleological character and is, in most cases, reductionist. ${ }^{1}$

DT was instrumental in helping achieve striking scientific and technological successes; through it, we began to understand the world around and as a result, to control it. Since the disciplinary divisions proved to be very successful, DT was perfected to a high degree of sophistication. However, as the complexity of the phenomena under considerations was recognized it became evident that some sort of inter, or crossdisciplinary approach has to be used in order to obtain a better understanding of the observed phenomena. Interdisciplinarity was born from an increasing effort (not always conscious) to cope with complexity. At first concepts developed in one domain were merely transferred to others but in time theories, logics and methodologies as well came to be transferred from one area of research to another in the course of interdisciplinary processes. It is quite reasonable therefore to ask the question 'is interdisciplinarity the necessary 'tool' for handling complexity' to which we must add, 'is it however also a sufficient one?'

Edgar Morin, one of the most prolific writers on the subject, attacked directly the problem stating that the disciplinarian divide is wrong because it creates artificial boundaries; disciplines, in fact, 'maim reality': 'le vrai problème est celui des disciplines, qui donnent toujours comme cadre de référence un découpage arbitraire et mutilant de la réalité.' ${ }^{2}$ As a corollary, Morin asks, 'Would an inter-disciplinarian approach then enable a better handling of the complexities encountered in any area of research?'. 'Not at all', is his answer, as interdisciplinarity 'does not bring together the pieces of the puzzle to form a comprehensive picture but rather tries to match heterogeneous entities like (independent) nations in a United Nation organization' (ibid.). The trouble with interdisciplinarity according to this interpretation is that while trying an approach of cross-fertilization and import from discipline to discipline, it preserves in the process its disciplinarian specificity. And this is wrong, says Morin, because the divisions we practiced so far are no longer justified. One reached a point beyond which reduction cannot work and there is no way to obtain further knowledge by separating the components of complex organisms and/or organizations, whether we talk about human society or economical systems. There are two things/ideas at work here: one related directly to the nature of the interdisciplinarian activity and the other, to its content or object (that is, its complexity). In this presentation I shall insist mostly on the first one; the second had been discussed extensively in my book, Complexity, Multi-disciplinarity and Beyond. ${ }^{3}$

Things are not so simple however even though the meaning of the (old) term, interdisciplinarity, seems self-evident. Still, one has the feeling that it either says too much or too little. In almost any book opened randomly one will find traces of 'interdisciplinarity': when a literary critic writes about novel or poetry, when somebody presents himself as a 'historian of religions', when a trained physicist muses about 'complex-systems theory' in economics and evolutionary biology, they all practice interdisciplinarity. But in the first two cases, the interdisciplinarian act is performed within a given discipline since both literary criticism and history of religions are autonomous and (fairly) well defined domains of research. In the other case, one might argue that the physicist introduces tools developed in his area of research to help (or mess up) things in a domain clearly outside his own. But if successful, he may transform economics in econo-physics (there is a serious journal with this title on the shelf of any respectable university library

\footnotetext{
${ }^{1}$ Interdisciplinarity - Toward the Definition of a Metadiscipline? (New York: Peter Lang, 2001), 3 and the chapter dedicated to DT (Chapter VI, 71-78). In the following I shall refer to it as Interdisciplinarity.

${ }^{2}$ The real problem is that of the (existince of the) disciplines which (always) create a system of reference based on an arbitrary and reality-botching divisions (my translation from E. Morin and M. Piattelli-Palmarini, Pour une anthropologie fondamentale, Paris: Editions du Seuil, 1974), 277.

${ }^{3}$ Michael Finkenthal, Complexity, Multi-disciplinarity and Beyond, Peter Lang, New York, 2008.
} 
today and all over the world many conferences on selected topics in this domain are held nowadays); in this, again, interdisciplinarity has been transformed into ... disciplinarity.

I should point out that in the context of DT, disciplinarity has always two meanings: one is that of a well defined domain of (re)search. The other meaning of this concept is related to that of discipline, rigor, and willingly accepted limitation. With these in mind, let us go back for a moment to the ancient Greeks ${ }^{4}$. The struggle to find ways to know and understand the world around and inside us as well as the agonizing question about how to ascertain the truth of these findings were a constant preoccupation of Ancient Greek philosophy. Plato and Aristotle made frequent references to the pre-Socratics, to Socrates and his contemporaries, to the Sophists. When all this was over, Greece has produced the basis and the intellectual tools for the interpretation of the world and of the inner self of the individual, for centuries to come: we knew from that point on what was worth studying, how to proceed about our inquiries and how to test the truth value of the conclusions we arrived at. In Book VII of his Physics, Aristotle writes that 'the original acquisition of knowledge is not a becoming or an alteration; for we are said to know and to understand when our intellect has reached a state of rest and came to a standstill...' ${ }^{5}$. Knowing is by its very nature static, it means to 'resonate' with something which is constant and eternal. But knowing means also to be disciplined and reach this state of resonance. Only that which is essential can be known, theory, that which I know, originates in the verb theorein, which meant primarily contemplation, observation. It is not surprising therefore that when Christianity took over the Roman world and instated the reign of its God over the pagan world and later, when Islam came in touch with this newly established Judeo-Christian civilization, Aristotle's philosophy was found acceptable by all and it was adopted as the main research tool. The Modern world which built upon these pillars turned out to be amazingly homogeneous from the point of view of its structural thinking patterns. Of course, the social, cultural and historical circumstances which influence all components of our intellectual endeavors changed many times and showed a large diversity along the historical gap of almost twenty centuries which separates ancient Greece from the beginnings of Modernity. But certain things found at the very roots of these intellectual activities barely changed if at all and one of these constants was the disciplinarian thinking. This is not to say necessarily that the Greek way of thinking was already 'disciplinarian'; for didactic purposes it will be perhaps appropriate to call it a quasi or pre-disciplinarian thinking.

The Greek pre-disciplinarian thinking seeks order and uses logic to codify both the ways of thinking and its conclusions. This is common to all sciences, high or low, hard or soft. This desideratum was an offspring of Socrates' idea concerning the consistency of all knowledge; in the dialogue bearing his name, he encourages Theaetetus 'just as you found a single character to embrace all that multitude, try also to find a single formula that applies to the many kinds of knowledge' ${ }^{\prime}$. This represents the essence of rationality, as conceived by the ancient Greeks: truth has to be the outcome of a self-consistent system of statements. The concept is the building block and logic is the binding material. 'The Greek definition of the rational as the statement of significant affinities exhibited in diverse things and of reason as the instrument which uncovers such community, becomes the dominant definition in philosophical tradition', wrote Herbert M. Garelick in Modes of Irrationality ${ }^{7}$ I would only amend the above quote slightly by pointing out that rational and reason, in the sense defined by the mentioned author do not represent the content of the philosophical tradition but its epistemological tools, the basic tenets of its thinking. This discipline has been maintained through the Middle Ages till the Renaissance. Garelick exemplifies this in the cases of Bruno, Kepler and Cusanus; moreover, one can find this component of DT originating in the Greek pre-disciplinarian way of thinking maintained to the point that it is clearly distinguishable even among the modern German idealist philosophers, such as Fichte and Hegel. 'A fundamental principle is exhausted when a complete system has been erected upon it, that is, when the fundamental principle

\footnotetext{
${ }^{4}$ Since the second chapter in my Interdisciplinarity book was entitled The Greek Way to DT, I will be careful not to repeat myself here but still, I shall build on some of the ideas expressed there.

${ }^{5} 247 \mathrm{~b} 10$.

${ }^{6} 148 \mathrm{~d}$.

${ }^{7}$ The Hague: Martinus Nijhoff, 1971, 4.
} 
necessarily leads to all the propositions deduced from it, and when, again, all deduced propositions necessarily lead back to it'.

What changed in between the pre-disciplinarian thinking and the DT? The 'visible' turning point was the Galilean-Newtonian revolution; however, the changes were, as always, gradual. It is more important however to define the nature of the change and its mechanisms rather than when this occurred as they will help us establish the relationship between DT and interdisciplinarity as well as that between them and complexity.

It seems to me that the distinction I made between the two concepts, rationality and reason, is very important in the context of the present discussion. Rationality is a general concept which addresses all the domains of human intellectual reflection; reason refers to the techniques of implementation. When I reflect upon life and death, destiny, happiness or the way our brain understands the surrounding world, I find myself in the realm of 'rationality'; the actual way in which I do, I implement things, the techniques I use, how do I study a specific thing/phenomenon in order to understand it (whatever that means), belong to the realm of 'reason'. The introduction of the idea of mathesis universalis and the change from contemplative to purpose driven research are the two new added values which make the Greek pre-DT into the modern disciplinarian thinking.

In his book entitled Radical Reflection, Calvin O. Schrag pointed out that the current crisis in the human sciences is due to an increased preoccupation with quantification and formalization ${ }^{9}$. The methodology associated with it implies 'the arrogation of a certain epistemic privilege to quantitatively directed inquiry' ${ }^{10}$. This is indeed a corollary of the GN revolution; the subtle point Schrag makes though is that this 'methodological naïvete', as he calls the process, by which quantification accedes to an epistemic privilege leads to a situation in which 'the experiential is pretentiously reduced to the experimental; and reality is prejudged as a statistical or measurable 'fact." 11 In the end, the whole discussion is one of 'fact' vs. 'value'. 'The fact-value distinction' writes Schrag, 'is itself a reified result of the confrontation of an abstracted empiricism with an objectified system of value' 12 . We need therefore, to go back to a proto-philosophical and proto-scientific stage and create a radical form of reflection which will re-establish the meaning of the fact and value and re-formulate in terms of this new outlook, the factvalue relationship at the base of any hermeneutic.

'We are conditioned to think epistemologically. And to think epistemologically is to think logically and methodologically. ${ }^{13}$ We must suspend our beliefs and suppositions conditioned by this DT thinking and through a radicalization of empiricism and an expanded concept of reason, re-create the tools for a new thinking-in-complexity. Radicalization of empiricism means a new understanding of the experiential; we should include the non-quantifiable as well as the measurable 'observables' which result from the interaction with the surrounding world. Value permeated concepts can be associated with operational ones in order to change their specific weight or to make them more adaptable to a different use. That way, in the process of transferring a concept from one discipline into another, its meaning changes to some extent; in this case I would prefer to talk of a multi-disciplinarian rather than interdisciplinarian effort (in which the concepts are transferred from domain to domain unchanged, the only criterion for their use under different circumstances being the fact that they fit well into a formalism, mostly mathematical or quasiformal at least).

In my book on interdisciplinarity, I spoke of positive (or successful), illusory and botched interdisciplinarity. ${ }^{14}$ This classification was based on a value judgment concerning the end result of the inter-disciplinarian endeavor. However, all my examples were chosen from the domain of 'hard' sciences

\footnotetext{
${ }^{8}$ Fichte in The Science of Knowledge, ap. J. Hartman (ed.), Philosophy of Recent Times (New York: Mc Graw-Hill, 1967), 20.

${ }^{9}$ Radical Reflection and the Origin of Human Sciences (West Fayette: Purdue University Press, 1980).

${ }^{10}$ Ibid., 5.

${ }^{11}$ Ibid., 6

${ }^{12}$ Ibid., 7.

${ }^{13}$ Ibid., 11.

${ }^{14}$ Interdisciplinarity, see $79-94$.
} 
(or almost all, economics being at the borderline of a 'hard' science today). Would the conclusions have been the same if I included in my consideration humanities and social sciences? And would have been the above mentioned criticism of interdisciplinarity brought forth by Morin be justified at all in this realm as well? The disciplinarian divide does not to seem to be very strong in the domain of cultural and social sciences: I am looking around to the books aligned on my bookshelves, I read the titles The Origins of Totalitarianism, What is Political Philosophy?, The Pursuit of Signs, Heidegger and the Poets, etc. and I wonder to discipline they belong. The first two, most probably can be assigned to political science, the third to semiotics, but the fourth? Is this a book of philosophy, literary criticism, political science (yes, political science since when Heidegger passed from Sein und Zeit to Hölderlin, politics was involved) or to ... semiotics (in a certain sense; one could object that I am probably exaggerating a bit here, but I could find justifying arguments in Derrida or Julia Kristeva). I quote randomly from one of the works mentioned above: Hannah Arendt writes that 'neither oppression nor exploitation as such is ever the main cause for resentment; wealth without visible function is much more intolerable because nobody can understand why it should be tolerated. ${ }^{15}$ Is this sociology, behavioral science, political theory or an attempt to make an observation pertinent to the field of mass-psychology? 'Neither tribal nationalism nor rebellious nihilism is characteristic of or ideologically appropriate to the masses as they were to the mob ${ }^{\prime 16}$. This sounds like sociology or anthropology or some combination of both, but what is the meaning of 'nihilism' when applied to collectivities (be they masses or a $m o b$ )? In between the two quotes, there are endless references to historical dates and facts linked often to philosophical commentaries; in view of all these, one may ask what kind of book did Hannah Arendt write and what is it exactly about? We ultimately get some sort of an explanation concerning the origins of the totalitarianism, but is that all it is there and was this her main purpose in writing the book?

It seems therefore that in the realm of humanities and social sciences interdisciplinarity is ultimately a very context dependent concept. That, mainly because in humanities as well as in the political and social research it is difficult to carve out easily well-defined disciplines and as a result, defining interdisciplinarity in these areas is more problematic than in 'hard' sciences. On the other hand, one can reject the typical 'scientism' which has often been related to interdisciplinarian activities (in particular the use of mathematical formalisms in domains external to the 'hard' sciences), without losing the ability to tackle complex and/or complicated problems. For all these reasons, we should use in the domain of humanities as well the concept of multi-disciplinarity (MD) rather than that of inter-disciplinarity. However, one must extend the meaning of MD beyond that of the simple mixing of various concepts borrowed from different disciplines. There must be something else also, some 'added value' has to be incorporated in the concepts used. For instance, when Heidegger discusses philosophy, literature and poetry (Dichtung in German means poetry, but not only; in a more general sense, it refers to literary creation in general), he moves them all to the common ground of 'enstrangement'. This (multidisciplinarian) act represents more than a simple bringing together of philosophy (or thinking in Heidegger's parlance) and poetry (literature). It might very well be that even if - at least in some instances - a hard core of rules and concepts which would describe a discipline could be found, the most productive results will be obtained outside this core, at the intersection between the different disciplines. That such disciplinarian 'cores' could be defined, was a fairly common belief during the reign of the structuralist orthodoxy in post-WWII European thought and again I have to bring up Edgar Morin who waged a strained battle against the metaphors of the separate 'continents' of physics, biology and/or other humanistic disciplines. Multi-disciplinarity re-defined as a form of inter-disciplinary enterprise which takes place in a 'fluid' zone of interference or commonality between disciplines can very well be positive and successful in becoming a new methodological research tool.

We observe this 'fluidity' (a quite fashionable term today) when we study the new, all-encompassing mega-discipline of cultural studies or in semiotics. The process might have started perhaps with the Russian 'formalists' at the beginning of the $20^{\text {th }}$ century some critics will point rather toward the end of it.

\footnotetext{
${ }^{15}$ The Origins of Totalitarianism (New York: Meridian Books, 1958), 4.

${ }^{16}$ Ibid., 317.
} 
In a way, both these schools of thought are to some extent right: the process of 'dissipation' of a discipline begins with the recognition of its complex character and is implemented through an inter-disciplinarian effort applied to something perceived prior to that moment, as being a well- defined discipline (even though, as we have already remarked, in humanities, the boundaries of a discipline cannot be defined as sharply as in natural sciences).

For a long time, aesthetics was for the arts what mathematics was for the 'hard' sciences: the unifying theory which produces the tools for the analysis of the work of art be it literary, plastic or musical. Economics was to become later such a theory for the social and political sciences and for some thinkers, even for the understanding of history. But there is no 'pure' muti-disciplinarity: there are always some 'interdisciplinarian residuals' left in it, such as for instance that of the use of aesthetic principles in science or of concepts borrowed from economics in the analysis of a literary text. They remain however insignificant as long as their use is strictly metaphoric and represent a mere device to guide our thinking rather than an analysis tool.

In this picture, philosophy - which in a way could be defined as 'thinking about thinking' - has a peculiar stance. Indeed, it was used, at various times and under specific forms, as underlying theoretical principle; in many instances however, the process was reversed so that the literary (or aesthetic) analysis became just another way of doing philosophy. There are many examples in this direction, all the way from Plato to Derrida. As an illustration we shall quote a contemporary philosopher, Roman Ingarden : 'Although the main subject of my investigations is the literary work ... the ultimate motives for my work on this subject are of a general philosophical nature. ${ }^{17}$ Lev Shestov was doing the same while writing about Chekhov or Dostoievski, as did his disciple Benjamin Fondane when he wrote about Rimbaud and Baudelaire. How do multi-disciplinarity and complexity interact under such circumstances?

We observe therefore that a more 'general' domain, such as philosophy, can be studied using tools borrowed to a more 'restricted' one, for instance a specific form of literature or criticism. In general, the opposite used to be the norm. One should notice though, that the two approaches are not symmetric: the typical situation is that of the recognition that an increased degree of complexity imposes a multidisciplinarian approach. In the case mentioned, the multi-disciplinarity precedes the acknowledgement of complexity. In order to be able to forge an understanding the tools used have to be ready before we get started: one has to accept a priori the multiple meanings of the concepts used in analysis.

Perhaps one has to take a radical approach and try to think of a re-definition of the idea of concept itself, instead of playing with definitions built on nuances. Multi-disciplinarity might require the introduction of multi-valued concepts even though the great success of the early Greek philosophy was due to the invention of the concept which defined an 'essence', the nature of something which in reality has multiple embodiments. In my book on inter-disciplinarity, I explained that DT is based upon this single-valued quantum of meaning which is the concept. Interdisciplinarity (IDT) as well as multidisciplinarity (MDT) imply both transfers of concepts from one field of observation (or area of creation) to another; however, in the process the concept is either kept constant (as in the case of the use of mathematical formalisms or the metaphoric use of concepts) or, it evolves through a continuous isomorphic process through which its content is modified. However, at the end of the process its single valued character is strictly conserved. The disciplinarian thinking is not only one which acts in a world of well defined domains of observation (i.e. disciplines), but it is also disciplined, in the sense that it conserves rigorously this original definition of the concept. Therefore IDT as well as MDT cannot solve the problems posed by complexity, as long as both rely solely on DT as defined above. Therefore, whether we change or not the meaning of a given concept transferred from one domain to aother, the problem is that in the end, the concept, modified or not in the process, remains single valued. Multi-disciplinarity is a necessary tool for approaching complexity but it is by no means sufficient.

\footnotetext{
${ }^{17}$ Roman Ingarden, The Literary Work of Art (Evanston: Northwestern University Press, 1973), 1xxii.
} 